\title{
THE LEGAL REGULATION OF THE RELATIONS IN OIL AND GAS PRODUCTION: THE PROBLEM STATEMENT
}

\author{
Anastasia N. Kuleshova \\ Moscow University of the Ministry of Internal Affairs of Russia named after V.Ya. Kikotya, Moscow, Russian Federation
}

Introduction: the paper deals with certain issues of the legal regulation of the relations in oil and gas production. The reasons for the fragmentary and non-systematic legal regulation of the economic relations for the planning and working of mines by the special legislation are highlighted. The paper considers the system of norms regulating the control in the Russian Federation, which requires further development regarding the establishment of sanctions for the violations of environmental safety and negative impact on the environment. The purpose of research: to analyze the features of the legal regulation of public relations in the oil and gas sector, identify the theoretical positions and problems of the law enforcement, and form recommendations for improving the legislation in this area. The research used the following methods: the general method (dialectical materialism); the general scientific methods (logical (induction, deduction, analysis and synthesis), system and functional); private law methods (formal legal, comparative legal). Results: the issues of the legal regulation of the regime of oil and petroleum products are considered, and the theoretical concepts are presented. The problems of the law enforcement based on the dual interpretation of the norms of law in the oil sector and, as a result, their incorrect application are identified. The problem of the local regulation of the fuel and economic complex is raised and the recommendation is made to generalize or fill in the gaps in the regulations in the sphere of regulating public relations in the oil and gas industry. Conclusion: the author substantiates the need to fill in the gaps in the legislation starting from the bylaw regulation and to rely on the practical experience of the companies in the field of oil and gas production. It is argued that it is possible to fill in the gaps in the law at the first stage by means of issuing orders from the ministries and departments.

Key words: legal regulation of oil and gas production, gaps in the legal regulation, industry norms of civil and business law, complex norms, unified norms, environmental harm.

Citation. Kuleshova A.N. The Legal Regulation of the Relations in Oil and Gas Production: The Problem Statement. Legal Concept, 2020, vol. 19, no. 3, pp. 103-107. (in Russian). DOI: https://doi.org/10.15688/lc.jvolsu.2020.3.14

ББК 67.404

Дата поступления статьи: 23.05.2020

УДК 347.44

Дата принятия статьи: 20.06.2020

\section{ПРАВОВОЕ РЕГУЛИРОВАНИЕ ОТНОШЕНИЙ ПО ДОБЫЧЕ НЕФТИ И ГАЗА: ПОСТАНОВКА ПРОБЛЕМЫ}

\author{
Анастасия Николаевна Кулешова \\ Московский университет МВД России им. В.Я. Кикотя, г. Москва, Российская Федерация
}

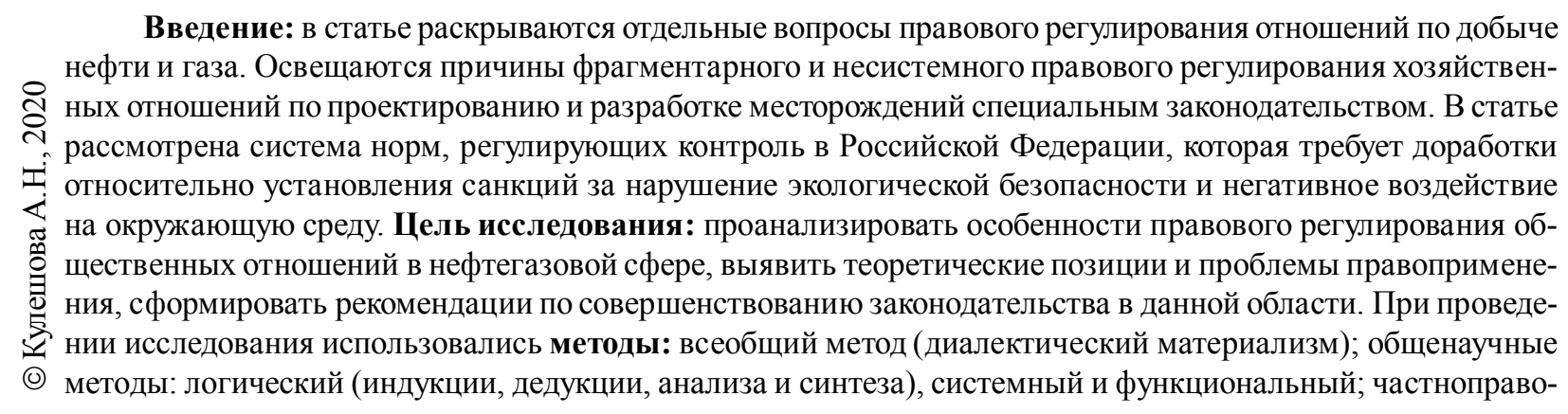


вые методы (формально-юридический, сравнительно-правовой). Результаты: рассмотрены вопросы правового регулирования режима нефти и нефтепродуктов, представлены теоретические концепции. Выявлены проблемы правоприменения, основанные на двойственном трактовании норм права в нефтяной сфере и, как следствие, их неверном применении. Поднята проблема локального регулирования топливно-экономического комплекса и дана рекомендация по обобщению или восполнению пробелов в нормативных актах в сфере регулирования общественных отношений в нефтегазовой отрасли. Вывод: обосновывается необходимость восполнения пробелов в законодательстве, начиная с подзаконного регулирования, с учетом опыта практической деятельности компаний в сфере нефте- и газодобычи. Утверждается, что восполнить пробелы в праве на первом этапе возможно посредством издания приказов министерств и ведомств.

Ключевые слова: правовое регулирование добычи нефти и газа, пробелы правового регулирования, отраслевые нормы гражданского и предпринимательского права, комплексные нормы, унифицированные нормы, экологический вред.

Цитирование. Кулешова А. Н. Правовое регулирование отношений по добыче нефти и газа: постановка проблемы // Legal Concept = Правовая парадигма. - 2020. - T. 19, № 3. - C. 103-107. - DOI: https://doi.org/ 10.15688/lc.jvolsu.2020.3.14

\section{Введение}

Добыча нефти и газа играет значительную роль в развитии экономики России, что, в свою очередь, требует как создания новых правовых норм, регулирующих отношения, связанные с добычей, так и совершенствования имеющихся. Как отмечает А.Б. Бондаренко, «...для подзаконного регулирования, безусловно, необходимо создавать правовую базу на уровне законодательных актов (пусть даже путем точечных изменений)» [1, с. 16].

Данную точку зрения разделяет В.В. Романова, которая, проанализировав особенности правового регулирования режима нефти и нефтепродуктов, пришла к выводу, что характерной особенностью правового регулирования общественных отношений в нефтяной отрасли является отсутствие специального закона, в котором содержались бы унифицированные правовые нормы, регулирующие общественные отношения в данной сфере (например, в газовой отрасли, в сфере электроэнергетики, теплоснабжения и др.) [10; 11; 13$]$. Однако «даже при отсутствии специального нормативного правового акта, регулирующего общественные отношения в нефтяной отрасли, сформировался особый правовой режим нефти, в частности: как стратегически важного энергетического ресурса, как опасного вещества, как товара, как объекта биржевой торговли; как объекта отношений по транспортировке магистральным трубопроводным транспортом, как объекта внешнеэкономических сделок» [5].

\section{Правовое регулирование отношений по добыче нефти и газа}

Нефтегазовое законодательство в Российской Федерации представлено следующим перечнем нормативных правовых актов, имеющих как общеправовое, так и специальное значение $[3 ; 8 ; 9 ; 12]$ :

1. Гражданский кодекс Российской Федерации (ч. II) [2], регулирующий отношения между субъектами права в части нефтегазовых соглашений ( $\$ 6$ гл. 30).

2. Федеральный закон Российской Федерации от 31 марта 1999 г. № 69-Ф3 «О газоснабжении в Российской Федерации» [10] определяет организационные, экономические и правовые основы отношений в сфере газоснабжения и направлен на удовлетворение потребностей государства в стратегических энергетических ресурсах.

3. Федеральный закон Российской Федерации от 17 августа 1995 г. № 147-Ф3 «О естественных монополиях» [7] направлен на достижение баланса интересов потребителей и субъектов естественных монополий, определяет правовые основы федеральной политики в отношении естественных монополий в Российской Федерации и обеспечивает доступность продаваемых потребителям товаров, а также эффективное функционирование самих субъектов естественных монополий.

Приведенный перечень не является исчерпывающим, но отражает основные положения федерального законодательства в этой области. В то же время, несмотря на доста- 
А.Н. Кулешова. Правовое регулирование отношений по добыче нефти и газа: постановка проблемы

точно серьезную нормативно-правовую базу, регулирующую нефтегазовый сектор, было бы неверно утверждать, что существующая в данной области система правовых норм является идеальной или достаточной для того, чтобы ее исполнители, в том числе судьи, могли эффективно применять соответствующие законы и подзаконные акты в ходе практической деятельности.

Несмотря на то что важной сферой для Российской Федерации является нефтегазовая отрасль, которая и формирует основной бюджет страны, до настоящего времени не урегулированы в полной мере и гражданско-правовые отношения.

Так, состояние нормативно-правового обеспечения деятельности хозяйствующих субъектов в нефтегазовом секторе свидетельствует о его фрагментарном и несистемном характере. Отсутствуют специальные законы, например: «О трубопроводном транспорте», «О разработке нефтяных месторождений», «О транспортировке нефти и нефтепродуктов» и др.

Как отмечают Р.Н. Салиева и 3.М. Фаткудинов, «...до настоящего времени не сформировалась системная база нормативных правовых актов, регламентирующих хозяйственную деятельность по проектированию и разработке месторождений...» [6, с. 3].

Важное значение для развития отрасли имеет и институт возмещения вреда, причиненного в процессе деятельности субъектов гражданского права. В силу этого нормативно-правовая база, регулирующая отношения в нефтедобывающей отрасли, включает в себя не только общие законодательные акты, но и специальные эколого-правовые нормы. Одной из основных целей при создании нормативно-правовых актов в области нефтедобычи и нефтепереработки следует ставить экологическую безопасность общества от загрязнений окружающей среды, а также обеспечение эффективной и бесперебойной работы.

Рассмотрев систему правовых норм, действующих в данной сфере, можно сделать вывод, что она является комплексной, но все же требует внесения некоторых изменений. Так, например, санкции, установленные за нарушение экологической безопасности и нега- тивное воздействие на окружающую среду, минимальны; отсутствуют стимулы или определенные «поблажки» для предприятий нефтедобывающего сектора, которые соблюдают эти требования и устанавливают свои собственные, более жесткие стандарты для недопущения аварийных ситуаций. Возможно, при установлении таких «поблажек» можно будет говорить о переходе на экологически эффективные технологии и дальнейшую модернизацию производства. Следовательно, важное значение при регулировании правоотношений имеет грамотное сочетание законодательных и корпоративных норм.

Как отмечает Р. Шакеров, «система экологического контроля и промышленной безопасности дополняется корпоративными требованиями, что способствует предотвращению аварийных ситуаций на месте добычи газа. Государственным органам в ходе оценки полного отсутствия аварий на длительном сроке необходимо выявлять передовой опыт, используемый в корпоративной практике нефтедобывающих компаний, и ряд требований (используемых в них) утверждать на законодательном уровне» $[14$, с. 8$]$.

Таким образом, целесообразно говорить о закреплении на законодательном уровне норм, опираясь на практическую деятельность компаний в сфере нефте- и газодобычи.

Важное значение при регулировании гражданско-правовых отношений в нефтегазовой сфере имеют подзаконные нормативноправовые акты. Приказом Минэнерго России от 19 июня 2003 г. № 231 утверждена Инструкция по контролю и обеспечению сохранения качества нефтепродуктов в организациях нефтепродуктообеспечения [4] для установления единых требований по контролю качества нефтепродуктов у индивидуальных предпринимателей и в организациях, которые осуществляют операции с нефтепродуктами, а именно прием, хранение, транспортировку и их отпуск. Таким образом, подзаконные акты заполняют пробелы в нормативно-правовой базе на более высоком уровне. Так, благодаря подзаконным актам устанавливается объем и график транспортировки нефти и газа по магистральным трубопроводам, а также ведется реестр субъектов, имеющих право на пользование данным трубопроводом. Исходя 
из этого, опять следует подчеркнуть, что характерной чертой правового регулирования нефтегазовой отрасли является восполнение законодательных пробелов посредством подзаконного нормотворческого регулирования. При этом важной отличительной особенностью является закрепление в подзаконных актах ряда положений, которые в обычной хозяйственной деятельности отражаются в договорах (например, объем и график транспортировки нефти и газа).

\section{Выводы}

Проведя анализ правовых актов, регулирующих нефтегазовую сферу, можно сделать вывод, что правовое регулирование общественных отношений в этой области не носит комплексный характер, так как нормы рассредоточены по всем отраслям права (в гражданском, административном, налоговом и др.), но, в свою очередь, это свидетельствует об отсутствии самостоятельной области нефтегазового права в системе российского права. Мы полагаем, что такой подход оправдывает себя, так как создание единой отрасли правового регулирования нефтегазового сектора невозможно в силу многообразия отношений, составляющих данную сферу (гражданско-правовые, административные, экологические, предпринимательские и пр.). Тем не менее, действующее законодательство требует совершенствования.

В заключение следует отметить, что текущее правовое регулирование топливно-энергетического комплекса носит локальный характер, а многочисленные проблемы обусловлены, в том числе, отсутствием обобщенного нормативного акта, устанавливающего основные принципы и подходы к регулированию отношений в нефтегазовой отрасли.

Каждый сектор в топливно-энергетическом комплексе регулируется собственным отдельным законом (законами) и подзаконными актами, принятыми в его (их) исполнение. Такой подход к правовому регулированию создает условия для неравномерного применения требований этих законов и, следовательно, для неосуществления или только частичного достижения поставленных целей и задач.

\section{СПИСОК ЛИТЕРАТУРЫ}

1. Бондаренко, А. Б. Состояние и перспективы правового регулирования отраслей ТЭК России / А. Б. Бондаренко // Энергетическое право. - 2015. № 2. - С. 15-20.

2. Гражданский кодекс Российской Федерации (часть вторая) от 26.01.1996 г. № 14-Ф3 // Собрание законодательства РФ. - 1996. - № 5. - Ст. 410.

3. Закон РФ от 21.02.1992 № 2395-1 «О недрах» // Российская газета. - 1992. - № 102.

4. Приказ Минэнерго России от 19 июня 2003 г. № 231 «Об утверждении Инструкции по контролю и обеспечению сохранения качества нефтепродуктов в организациях нефтепродуктообеспечения» // Бюллетень нормативных актов федеральных органов исполнительной власти. - 2003. - № 41.

5. Романова, В. В. Об особенностях правового режима нефти и нефтепродуктов / В. В. Романова // Энергетическое право. - 2014. - № 2. - С. 11-15.

6. Салиева, Р. Н. Правовые проблемы регулирования нефтегазодобычи / Р. Н. Салиева, 3. М. Фаткудинов // Российская юстиция. - 2009. № 4. - С. 2-5.

7. Федеральный закон от 17.08.1995 г. № 147Ф3 «О естественных монополиях» // Собрание законодательства РФ. - 1995. - № 34. - Ст. 3426.

8. Федеральный закон РФ от 30.12.1995 г. № 225Ф3 «О соглашениях о разделе продукции» // Собрание законодательства РФ. - 1996. - № 1. - Ст. 18.

9. Федеральный закон РФ от 21.07.1997 г. № 116-Ф3 «О промышленной безопасности опасных производственных объектов» // Собрание законодательства РФ. - 1997. - № 30. - Ст. 3588.

10. Федеральный закон от 31.03.1999 г. № 69Ф3 «О газоснабжении в Российской Федерации» // Собрание законодательства РФ. - 1999. - № 14. Ст. 1667.

11. Федеральный закон от 26.03.2003 г. № 35Ф3 «Об электроэнергетике» // Собрание законодательства РФ. - 2003. - № 13. - Ст. 1177.

12. Федеральный закон РФ от 26.07.2006 г. № 135-Ф3 «О защите конкуренции» // Российская газета. - 2006. - № 162.

13. Федеральный закон от 27.07.2010 г. № 190Ф3 «О теплоснабжении» // Собрание законодательства РФ. - 2010. - № 31. - Ст. 4159.

14. Шакеров, Р. Законодательное обеспечение нефтедобычи / Р. Шакеров // ЭЖ-Юрист. - 2017. №31. - C. 8 .

\section{REFERENCES}

1. Bondarenko A.B. Sostoyanie i perspektivy pravovogo regulirovaniya otrasley TEK Rossii [Status and Prospects of Legal Regulation of Russia's Fuel 
А.Н. Кулешова. Правовое регулирование отношений по добыче нефти и газа: постановка проблемы

and Energy Complex Branches]. Energeticheskoe pravo, 2015, no. 2, pp. 15-20.

2. Grazhdanskiy kodeks Rossiyskoy Federatsii (chast vtoraya) ot 26.01.1996 g. № 14-FZ [The Civil Code of the Russian Federation (part two) of 26 January 1996 no. 14-FL]. Sobranie zakonodatelstva Rossiyskoy Federatsii [Collection of Legislation of the Russian Federation], 1996, no. 5, art. 410.

3. Zakon RF ot 21.02.1992 № 2395-1 «O nedrakh» [The Law of the Russian Federation of 21 February 1992 no. 2395-1 "On the Bowels"]. Rossiyskaya gazeta [Russian Newspaper], 1992, no. 102.

4. Prikaz Minenergo Rossii ot 19 iyunia 2003 g. № 231 «Ob utverzhdenii Instruktsii po kontrolyu i obespecheniyu sokhraneniya kachestva nefteproduktov v organizatsiyakh nefteproduktoobespecheniya» [Order of the Ministry of Energy of Russia of 19 June 2003 no. 231 "On Approval of the Instructions for Monitoring and Ensuring the Preservation of the Quality of Petroleum Products in Petroleum Product Supply Organizations"]. Byulleten normativnykh aktov federalnykh organov ispolnitelnoy vlasti, 2003, no. 41.

5. Romanova V.V. Ob osobennostyakh pravovogo rezhima nefti i nefteproduktov [On Peculiarities of Legal Regime of Oil and Oil Products]. Energeticheskoe pravo, 2014, no. 2, pp. 11-15.

6. Salieva R.N., Fatkudinov Z.M. Pravovye problemy regulirovaniya neftegazodobychi [Legal Issues of Oil and Gas Regulation]. Rossiyskaya yustitsiya, 2009, no. 4, pp. 2-5.

7. Federalnyy zakon ot 17.08.1995 g. № 147-FZ «O estestvennykh monopoliyakh» [Federal Law of 17 August 1995 no. 147-FL “On Natural Monopolies”]. Sobranie zakonodatelstva Rossiyskoy Federatsii [Collection of Legislation of the Russian Federation], 1995, no. 34, art. 3426.

8. Federalnyy zakon RF ot 30.12.1995 g. № 225$\mathrm{FZ}$ «O soglasheniyakh o razdele produktsii» [Federal
Law of the Russian Federation dated 30 December 1995 no. 225-FL "On Production Sharing Agreements"]. Sobranie zakonodatelstva Rossiyskoy Federatsii [Collection of Legislation of the Russian Federation], 1996, no. 1, art. 18.

9. Federalnyyzakon RF ot 21.07.1997 g. № 116-FZ «O promyshlennoy bezopasnosti opasnykh proizvodstvennykh obyektov»» [Federal Law of the Russian Federation of 21 July 1997 no. 116-FL "On the Industrial Safety of Hazardous Production Facilities"]. Sobranie zakonodatelstva Rossiyskoy Federatsii [Collection of Legislation of the Russian Federation], 1997, no. 30, art. 3588.

10. Federalnyy zakon ot 31.03.1999 g. № 69-FZ «O gazosnabzhenii v Rossiyskoy Federatsii» [Federal Law dated 31 March 1999 no. 69-FL "On Gas Supply in the Russian Federation"]. Sobranie zakonodatelstva Rossiyskoy Federatsii [Collection of Legislation of the Russian Federation], 1999, no. 14, art. 1667.

11. Federalnyy zakon ot 26.03.2003 g. № 35-FZ «Ob elektroenergetike» [Federal Law of 26 March 2003 no. 35-FL "On the Electric Power Industry"]. Sobranie zakonodatelstva Rossiyskoy Federatsii [Collection of Legislation of the Russian Federation], 2003, no. 13, art. 1177.

12. Federalnyy zakon RF ot 26.07.2006 g. № 135$\mathrm{FZ}$ «O zashchite konkurentsii» [Federal Law of the Russian Federation of 26 July 2006 no. 135-FL "On the Protection of Competition"]. Rossiyskaya gazeta [Russian Newspaper], 2006, no. 162.

13. Federalnyy zakon ot 27.07.2010 g. № 190-FZ «O teplosnabzhenii» [Federal Law of 27 July2010 no. 190FL “On Heat Supply"]. Sobranie zakonodatelstva Rossiyskoy Federatsii [Collection of Legislation of the Russian Federation], 2010, no. 31, art. 4159.

14. Shakerov R. Zakonodatelnoe obespechenie neftedobychi [Legislative Support of Oil Production]. EZh-Yurist, 2017, no. 31, p. 8.

\section{Information About the Author}

Anastasia N. Kuleshova, Junior Scientific Assistant, Department of Civil and Labor Law, Civil Procedure, Moscow University of the Ministry of Internal Affairs of Russia named after V.Ya. Kikotya, Akademika Volgina St, 12, 117997 Moscow, Russian Federation, Nastiaky@yandex.ru, https://orcid.org/0000-0002-4191-3047

\section{Информация об авторе}

Анастасия Николаевна Кулешова, адъюнкт кафедры гражданского и трудового права, гражданского процесса, Московский университет МВД России им. В.Я. Кикотя, ул. Академика Волгина, 12, 117997 г. Москва, Российская Федерация, Nastiaky@yandex.ru, https://orcid.org/0000-0002-4191-3047 